Int. J. Electrochem. Sci., 13 (2018) $3588-3600$

\title{
Corrosion Behaviour of Co-Cr Dental Alloys Processed by Alternative CAD/CAM Technologies in Artificial Saliva Solutions
}

\author{
Cristina E Savencu ${ }^{l, *}$, Liviu V Costea ${ }^{2}$, Mircea L Dan ${ }^{2}$, Liliana Porojan ${ }^{1}$ \\ ${ }^{1}$ Department of Dental Prostheses Technology, School of Dentistry, University of Medicine and \\ Pharmacy V. Babeș, Timișoara, Romania \\ ${ }^{2}$ Faculty of Industrial Chemistry and Environmental Engineering, Politechnica University of \\ Timișoara, Romania \\ *E-mail: cristina.savencu@ umft.ro
}

doi: $10.20964 / 2018.04 .40$

Received: 18 November 2017 / Accepted: 30 January 2018 / Published: 6 March 2018

The purpose of this study was to evaluate the corrosion behaviour of cobalt-chromium dental alloys processed by alternative computer assisted technologies compared to conventional casting technology. Samples obtained by CAD/CAM milling (MIL), Selective Laser Sintering (SLS), Selective Laser Melting (SLM) and conventional melting- casting technology (CAS) were subjected to different electrochemical techniques: linear polarization (LV), cyclic voltammetry (CV), electrochemical impedance spectroscopy (EIS) and chronoelectrochemical studies (chronoamperometry - CA and chronopotentiometry - CP). These methods have been successfully employed in the investigation of various corrosion processes in the field of dentistry. The corrosive electrolyte used for the electrochemical tests was Fusayama artificial saliva with $\mathrm{pH}$ values of 5.5, close to the physiological value. The temperature was kept constant at $37^{\circ} \mathrm{C}$. The samples were analysed by scanning electron microscopy (SEM) before and after performing corrosion testing. Computer assisted processing technologies showed promising results, representing a good alternative to traditional manufacturing methods for metallic frameworks for dental prostheses.

Keywords: corrosion resistance, electrochemical behaviour, Selective Laser Sintering, Selective Laser Melting, dental alloy milling, biomaterials, metal casting

\section{$\underline{\text { FULL TEXT }}$}

(C) 2018 The Authors. Published by ESG (www.electrochemsci.org). This article is an open access article distributed under the terms and conditions of the Creative Commons Attribution license (http://creativecommons.org/licenses/by/4.0/). 